\title{
Correspondence
}

\section{Iritis in Reiter's disease: an example of the Auer principle}

TO THE EDITOR, British Journal of Ophthalmology

SIR, Auer (1920) noted the effects of local inflammation in serum sickness. Xylol was used to produce local inflammation in the ear of a rabbit with serum sickness, The treated ear became inflamed and gangrenous, while the other ear remained unaffected. Similar experiments were carried out in a rabbit's eye (Gamble et al., 1970), where, after an intravenous dose of bovine serum albumin (BSA), 1 eye was given an intravitreous injection of it had resolved a further parenteral injection of BSA produced an acute iritis only in the eye injected with endotoxin. One explanation put forward for these reactions was that under appropriate conditions circulating immune complexes localised into that area associated with inflammation.

Acute iritis is a recognised complication of Reiter's disease, occurring in $8 \%$ of patients (Csonka, 1972), but its cause is unknown. We would like to report a case of Reiter's disease whose development of iritis may be an example of Auer's principle.

A 44-year-old male, HLA B27 positive, was diagnosed as having Reiter's disease in 1958 when he developed urethritis, conjunctivitis, and arthritis, the latter involving the knees and ankles. He was troubled with recurrent iritis in the right eye in 1958, 1963, and 1967, for which he was treated with a partial iridectomy in 1967. In 1971 he developed low back pain and at that time was noted to have radiological changes of bilateral sacroiliitis and ankylosis of the thoracolumbar spine. In 1972 he developed further arthritis in the knees and ankles, which settled with non-steroidal anti-inflammatory drugs. In May 1977 he receved a blow over the right eye and developed bruising of the eyelids but no obvious local damage to the eye. Five days later he developed an acute iritis, which resolved after 2 weeks' treatment with topical corticosteroids. At that time his peripheral joints were inactive, he had minimal back pain, and his therapy was indomethacin $100 \mathrm{mg}$ a day. Laboratory investigations showed an erythrocyte sedimentation rate (ESR) of $10 \mathrm{~mm}$ in 1 hour, C-reactive protein $1.44 \mathrm{mg} / 100 \mathrm{ml}$ (normal $<0.8 \mathrm{mg} / 100 \mathrm{ml}$ ), and circulating immune complexes as detected by the method of Hay et al. (1976) were greater than 3 standard deviations above the normal range. Six months later he had only bilateral Achilles and the animal was then given a repeat injection of serum. endotoxin. Local inflammation was produced, and when

\section{CASE REPORT}

tendonitis, and there had been no further attacks of iritis. The ESR was $41 \mathrm{~mm}$ in 1 hour, C-reactive protein $3.1 \mathrm{mg} / 100 \mathrm{ml}$, and circulating immune complexes remained elevated.

\section{COMMENT}

This was the first attack of iritis experienced by this patient in $\mathbf{1 0}$ years, so that its occurrence following the blow over the eye is unlikely to be coincidental. Gamble et al. (1970) concluded that damage to the uveal vasculature appeared to be necessary to facilitate deposition of circulating immune complexes and the development of iritis. Concussion to the iris, no matter how small, produces vascular changes in the uveal vessels. These consist initially of an ischaemic spasm, followed by a prolonged reactive vasodilatation and hyperaemia of the uveal tract (Duke-Elder, 1972).

Compared with normal controls this patient had elevated levels of circulating immune complexes, as measured by the solid phase $\mathrm{Clq}$ radioimmunoassay, before and after his episode of acute iritis. This patient may be an example of the Auer principle, in that vascular changes occurring after the blow to the eye enabled the deposition of circulating immune complexes in the iris, causing acute iritis. The cause of iritis in Reiter's disease is unknown, but his case leads to speculation that it could be secondary to deposition of circulating immune complexes.

Guy's Arthritis Research Unit,

Guy's Hospital Medical School,

London SE1 9RT

\section{References}

Auer, J. (1920). Local autoinoculation of the sensitized organism with foreign protein as a cause of abnormal reactions. Journal of Experimental Medicine, 32, 427-446.

Gamble, C. N., Aronson, S. B., and Brescia, F. S. (1970). Experimental Uveitis. I. The production of recurrent immunological (Auer) uveitis and its relationship to increased uveal vascular permeability. Archives of Ophthalmology, 84, 321-330.

Csonka, G. W. (1972). Reiter's disease. British Journal of Hospital Medicine, 7, 8-12.

Hay, F. C., Nineham, Lynn, J., and Roitt, I. M. (1976). Routine assay for the detection of immune complexes of known immunoglobulin class using solid phase C1q. Clinical and Experimental Immunology, 24, 396-400.

Duke-Elder, S. (1972). System of Ophthalmology, 1st edn. Vol. 14, p. 89. Henry Kimpton: London.

\section{Notes}

\section{Search}

The Applied Vision Association and the Ergonomics Society will hold a symposium on 'Search and the human observer' at Loughborough University of Technology on 3-5 January. Further details from Murray
Sinclair, University of Technology, Loughborough, Leics LE11 3TU (Tel. Loughborough (0509) 63171, ext. 392). 